\title{
Incidence trends and mortality rates of gastric cancer in Israel
}

\author{
Ron Lavy • Andronik Kapiev • Natan Poluksht • \\ Ariel Halevy $\cdot$ Lital Keinan-Boker
}

Received: 5 February 2012/ Accepted: 17 March 2012/Published online: 24 April 2012

(c) The International Gastric Cancer Association and The Japanese Gastric Cancer Association 2012

\begin{abstract}
Background Gastric cancer is the fourth most common malignancy worldwide. The incidence trends and mortality rates of gastric cancer in Israel have not been studied in depth. The aim of our study was to try and investigate the aforementioned issues in Israel in different ethnic groups.

Methods This retrospective study is based on the data of The Israel National Cancer Registry and The Central Bureau of Statistics. Published data from these two institutes were collected, summarized, and analyzed in this study.

Results Around 650 new cases of gastric cancer are diagnosed yearly in Israel. While we noticed a decline during the period 1990-2007 in the incidence in the Jewish population (13.6-8.9 and 6.75-5.42 cases per 100,000 in Jewish men and women, respectively), an increase in the Arab population was noticed (7.7-10.2 and 3.7-4.2 cases per 100,000 in men and women, respectively). Ageadjusted mortality rates per 10,000 cases of gastric cancer decreased significantly, from 7.21 in 1990 to 5.46 in 2007, in the total population. The 5 -year relative survival showed a slight increase for both men and women.

Conclusion There is a difference in the incidence and outcome of gastric cancer between the Jewish and Arab
\end{abstract}

R. Lavy · A. Kapiev · N. Poluksht · A. Halevy $(\bowtie)$ Division of Surgery, Assaf Harofeh Medical Center, Zerifin 70300, Israel, affiliated to the Sackler Faculty of Medicine, Tel-Aviv University, Ramat Aviv, Israel e-mail: ahalevi@asaf.health.gov.il

L. Keinan-Boker

Israel Center for Disease Control, Ministry of Health,

Ramat Gan, Israel

L. Keinan-Boker

School of Public Health, University of Haifa, Haifa, Israel populations in Israel. The grim prognosis of gastric cancer patients in Israel is probably due to the advanced stage at which gastric cancer is diagnosed in Israel.

Keywords Gastric cancer $\cdot$ Incidence $\cdot$ Trends $\cdot$ Mortality

\section{Introduction}

The incidence of gastric cancer (GC) has been continuously decreasing during the past four decades [1,2]. This change is evident in both men and women and in both developed and third-world countries [3]. In spite of this decline, GC is still one of the major causes of cancer-related death worldwide and is regarded as third only to lung and colon cancer [4] in this regard. The American Cancer Society estimated that 22,280 Americans (13,400 men and 8,880 women) would be diagnosed with stomach cancer in 2006 and that 11,430 Americans would die as a result of this disease during the same year [5].

Although not fully understood, the incidence of GC varies from country to country, being highest in Japan, Taiwan, Korea, and South America, but decreasing to a minimum incidence in Africa and Western Europe [4, 6].

Not only a decrease in the incidence of GC is documented, but also a significant change in tumor location, with a decrease in the rate of distal GC as compared to an increase in cancer of the esophagogastric junction [7-9].

The aim of our review was to report on the incidence trends and mortality rates of GC in Israel.

\section{Materials and methods}

The Israel National Cancer Registry (INCR) was established in 1960, and since 1982 it has been compulsory that 
all newly diagnosed cancers in Israeli residents be reported to this registry. Data collected by the INCR include demographic information (sex, date of birth, country of birth, date of immigration to Israel if applicable, and date of death if applicable), date and location of cancer diagnosis, histological type of the malignant tumor, and disease stage at diagnosis. The completeness of this registry is estimated to be approximately $93 \%$ for solid tumors [9].

Because the INCR database is linked annually with that of the population registry to ascertain the vital status of the registered subjects, survival rates can also be computed. In order to take into account the survival rates of the general population, relative survival rates are computed by dividing the observed survival of cancer patients by the expected survival in the general population adjusted for age, sex, and ethnicity, based on national data.

The Central Bureau of Statistics (CBS) collects information on mortality and codes the specific causes of death. Data on gastric cancer mortality rates were obtained for 1990 through 2007. In addition, the CBS provides annual population demographic data, which enable the calculation of rates in general and rates by specific age and population groups.

We first compared the two ethnic groups (Jews and Arabs) with respect to GC incidence and mortality rates, age-adjusted to the world standard population. The statistical significance of the time trends in each population group was examined by applying a linear regression model (where calendar year served as the independent variable and the corresponding annual rate as the dependent variable) and computing the $p$ value of the resulting regression coefficient (i.e., testing the hypothesis that the slope is significantly different from 0 ). The differences in the time trends between population groups were computed by applying a linear regression model, where calendar year served as the independent variable and the difference between corresponding annual rates of the two groups served as the dependent variable, and by computing the $p$ value of the regression coefficient.

Relative survival rates were computed for GC cases as the ratio of 5-year survival in cancer patients by the survival expected in the general population, matched for population group, gender, age and time period, based on national mortality rates published by the CBS.

The alpha level was set as 0.05 for all analyses, and all tests were two-sided. All analyses were done using IBM SPSS Statistics, Version 18.00 for Windows (IPSS Inc, Chicago, Illinois).

\section{Results}

Around 650 new cases of GC are diagnosed each year in Israel. From 1990 through 2007, age-adjusted GC

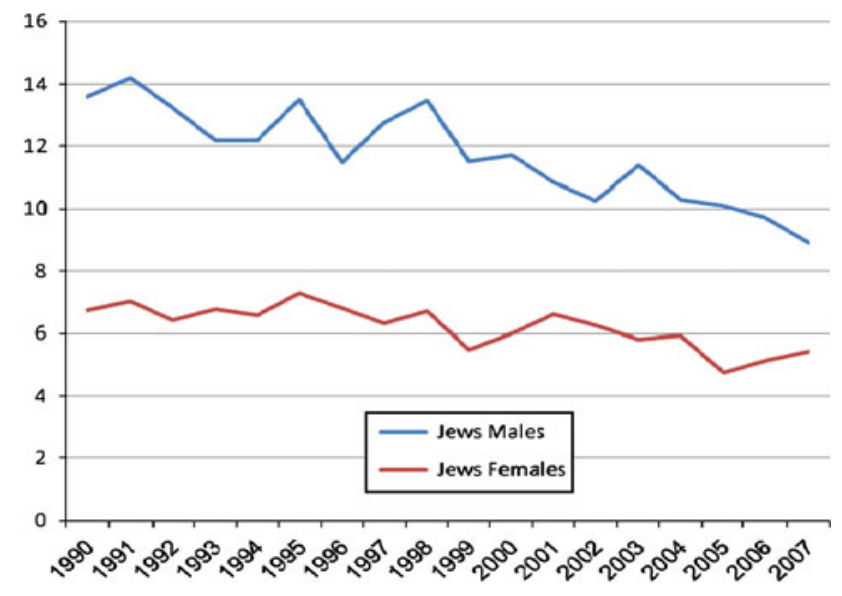

Fig. 1 Gastric cancer incidence rates (per 100,000)—Jews, Israel, 1990-2007

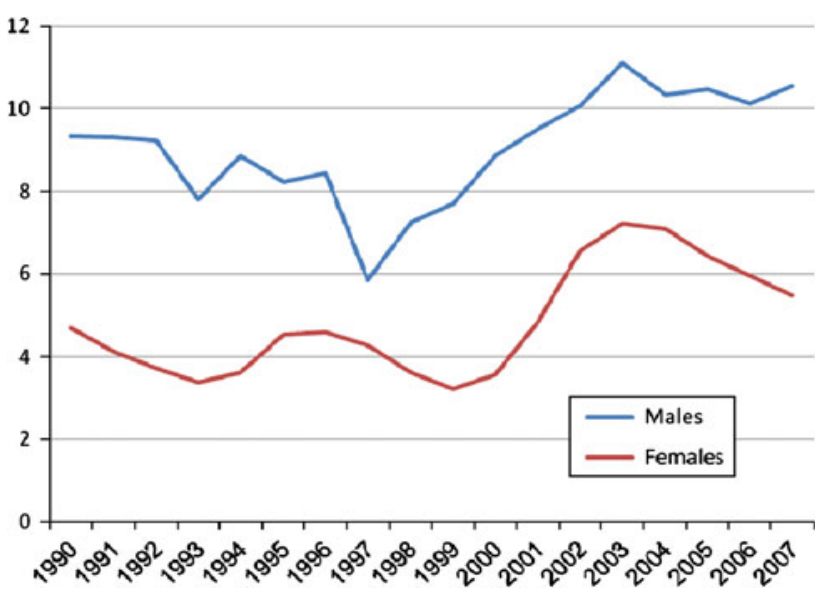

Fig. 2 Gastric cancer incidence rates (per 100,000)—Arabs, Israel, 1990-2007

incidence rates (per 100,000) decreased from 13.6 to 8.9 cases $(34.5 \%, p<0.0001)$ and from 6.75 to 5.42 cases per $100,000(19.7 \%, p<0.0001)$ in Jewish men and women, respectively (Fig. 1).

In Arabs, the rates increased non-significantly, from 7.7 to 10.2 cases per $100,000(32.5 \%, p=0.1768)$ in men, and significantly, from 3.7 to 4.2 cases per $100,000(13.5 \%$, $p=0.0378$ ) in women. Throughout 1990-2007, most patients were diagnosed at age 65 years and over among Jews and at age 55 or over among Arabs. (Fig. 2).

Age-adjusted mortality rates from GC (per 100,000) decreased significantly $(p<0.0001)$, by $24.3 \%$, from 7.21 in 1990 to 5.46 in 2007 in the total population.

Relative survival was assessed by year of diagnosis: the 5-year relative survival rate for men diagnosed in 1990-1994 was $20.2 \%$, and the rates increased to 23.9 and $26.5 \%$ for men diagnosed in 1995-1999 and 2000-2004, respectively. A similar trend was observed for women; the 
Fig. 3 Gastric cancer relative survival by year of diagnosismales, Israel, 1990-2009 (left) and gastric cancer relative survival by year of diagnosisfemales, Israel, 1990-2009 (right)
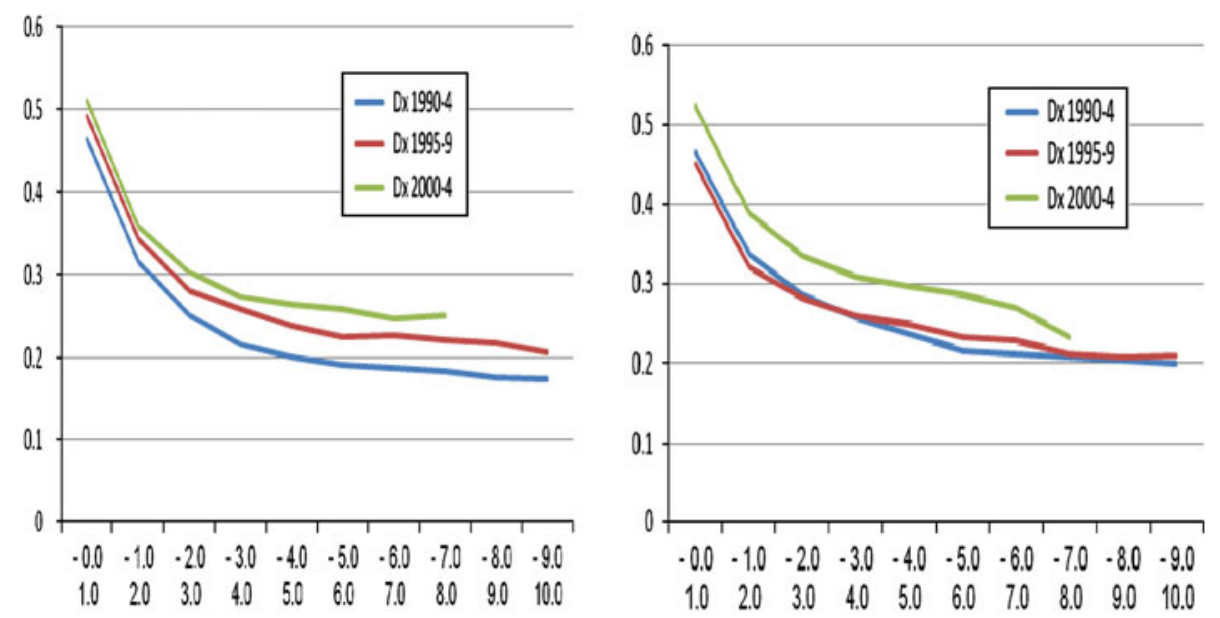

Numbers on the $x$-axis represent years of survival

Table 1 Five-year survival rates

\begin{tabular}{lll}
\hline & Women $(\%)$ & Men $(\%)$ \\
\hline $1990-1994$ & 23.6 & 20.2 \\
$1995-1999$ & 25.0 & 23.9 \\
$2000-2004$ & 29.6 & 26.5 \\
\hline
\end{tabular}

corresponding proportions were 23.6, 25.0, and $29.6 \%$, respectively (Fig. 3; Table 1).

\section{Discussion}

GC occupies the fourth place in the list of most common malignancies and is the second leading cause of cancerrelated death internationally [10]. Based on the study by Kamangar et al. [11], it becomes evident that 933,294 new cases of GC are diagnosed annually worldwide and 699,803 patients will die of the disease, with a mortality to incidence rate ratio of 0.74 in males and 0.77 in females.

Huge geographical differences are reported in the world literature regarding the incidence and trends of GC in different continents [12-14].

The aim of our study was to report on the incidence, trends, and mortality rates of GC patients in Israel.

As of 2011, the overall population of Israel amounted to $7.75 \times 10^{6}$, of whom $75.3 \%$ were Jews and $20.5 \%$ were of Arabic origin.

In contrast to the incidence and world trends that show a constant decrease [2,15], in Israel the number of cases of GC per years remains consistently approximately the same, at around 650 cases per year. However, when taking into account the overall increase in the Israeli population in the past $10-15$ years, based on the massive immigration of
Russian Jews, one can see a trend of decreasing incidence, especially in Jews.

Israel, as a melting pot for all Jews worldwide immigrating to Israel, is an interesting field of statistical analysis regarding different diseases based on the country of origin, with special attention to Jews of oriental origin (Tunisia, Iraq, Morocco, Yemen) as compared to Europeans and Americans (North and South) and new immigrants of Russian origin. Moreover, the Israeli population is not only a mix of Jews immigrating from all over the world, but also a mix of the Jewish and Arab populations.

The data collected by us show that during the period 1990-2000, the incidence of GC in the Jewish population was significantly higher than that in the Arab population. However, in 2000 through 2007, the incidence of GC increased substantially in the Arab population and concurrently decreased in the Jewish population, causing this observed incidence gap to become statistically insignificant.

Rosen et al. [9] tried to find an explanation for the differences in GC incidence between Jews and Arabs, and suggested that chronic alcohol intake was not the cause in the Jewish population and certainly not in the Moslem population (where alcohol is prohibited), nor could they show nutritional deficiencies. One of the explanations that they suggested was that Arab men smoke more tobacco than Jewish men and tend to suffer more from diabetes mellitus and obesity. This was confirmed by the survey on obesity in Jewish and Arab men and women published by Keinan-Boker et al. [16]. A genetic component that might explain the differences in the incidence of cancer between the Arab and the Jewish populations was demonstrated in patients with breast cancer [17], but to the best of our knowledge was not proven in GC patients. The expression of the E-cadherin mutation and the association between epithelial growth factor polymorphisms and GC risk may 
be one of the next issues to be investigated in regard to this subject [18].

The role of Helicobacter pylori in gastric carcinogenesis is unclear, but $H$. pylori infection is thought to predispose carriers to develop GC [19]. The prevalence of infection with $H$. pylori was found to be different in selected Jewish groups, ranging from 38 to $54 \%$ in young males of European and non-European origin, respectively, whereas it was $72 \%$ in a specific group of Kibbutz members [20].

We were unable to evaluate GC on the basis of the country of origin of the individual patients because data on birth places from the CBS is collected by continent of birth and rates cannot be calculated by specific countries of origin.

The data reported by the INCR were incomplete with respect to the stage of disease at diagnosis and the initial treatment, so we have no data on this particular aspect. However, out of more than 400 patients with GC operated on at our medical center, two-thirds presented with an advanced stage of the disease (Stage III-IV). This advanced stage is a common finding in the Western hemisphere, as compared to earlier stages of the disease in the East (where they have national cancer screening programs), and is the basis for the poor overall survival figures [21] observed in Israel. The overall survival figures of GC patients in Israel (as part of the Western hemisphere countries) are grim when compared to the results in the East [22, 23], although a very slight increase can be noticed in the overall survival figures over the years.

A critical change in tumor location is an ongoing process among GC patients. Rosen et al. [9] reported recently on an increasing rate of esophagogastric junction cancers as opposed to a decrease in distal gastric cancers.

In conclusion, the overall number of GC patients in Israel has remained stable at around 650 new patients per year during the past 15 years. While a decrease in the incidence can be noticed in Jews, an increase is noticed in the Arab population. The overall survival of GC patients in Israel is poor due to the advanced stage at diagnosis. However, a very slight increase in relative survival is reported.

Acknowledgments The authors have no commercial associations, financial disclosures, or other conflicts of interest to report with regard to this article. There are no sources of support for the work in the form of grants, equipment, drugs, or any combination of these.

\section{References}

1. Sano T, Sasako M, Yamamoto S, Nashimoto A, Kurita A, Hiratsuka M, Tsujinaka T, et al. Gastric cancer surgery: morbidity and mortality results from a prospective randomized controlled trial comparing D2 and extended para-aortic lymphadenectomyJapan Clinical Oncology Group study 9501. J Clin Oncol. 2004;22:2767-73.
2. Hartgrink HH, van de Velde CJ, Putter H, Bonenkamp JJ, Klein Kranenbarg E, Songun I, et al. Extended lymph node dissection for gastric cancer: who may benefit? Final results of the randomized Dutch Gastric Cancer Group trial. J Clin Oncol. 2004;22:2069-2077.

3. Jemal A, Center MM, DeSantis C, Ward EM. Global patterns of cancer incidence and mortality rates and trends. Cancer Epidemiol Biomarkers Prev. 2010;19:1893-907.

4. Verdecchia A, Corazziari I, Gatta G, Lisi D, Faivre J, Forman D, et al. Explaining gastric cancer survival differences among European countries. Int J Cancer. 2004;109:737-41.

5. Schlansky B, Sonnenberg A. Explaining gastric cancer survival differences among European countries. Am J Gastroenterol. 2011;106:1978-85.

6. Imamura Y, Yoshimi I. Comparison of cancer mortality (stomach cancer) in five countries: France, Italy, Japan, UK and USA from the WHO Mortality Database (1960-2000). Jpn J Clin Oncol. 2005;35:103-5.

7. Deans C, Yeo MS, Soe MY, Shabbir A, Ti TK, So JB. Cancer of the gastric cardia is rising in incidence in an Asian population and is associated with adverse outcome. World J Surg. 2011;35: 617-24.

8. Jézéquel J, Bessaguet C, Verveur C, Faycal J, Richert Z, Metges $\mathrm{JP}$, et al. Trends in incidence, management, and survival of gastric and cardia carcinomas in the area of Finistere (France) between 1984 and 2003. Eur J Gastroenterol Hepatol. 2010;22: 1412-9.

9. Rozen P, Liphshitz I, Barchana M. The changing epidemiology of upper gastrointestinal cancers in Israel: clinical and screening implications. Eur J Cancer Prev. 2009;18:191-8.

10. Engel LS, Chow WH, Vaughan TL. Population attributable risks of esophageal and gastric cancers. J Natl Cancer Inst. 2003;95: 1404-13.

11. Kamangar F, Dores GM, Anderson WF. Patterns of cancer incidence, mortality, and prevalence across five continents: defining priorities to reduce cancer disparities in different geographic regions of the world. J Clin Oncol. 2006;24:2137-50.

12. Buffart TE, Louw M, van Grieken NC, Tijssen M, Carvalho B, Ylstra B, et al. Gastric cancers of Western European and African patients show different patterns of genomic instability. BMC Med Genomics. 2011;4:7.

13. Sugai T, Habano W, Uesugi N, Jao YF, Nakamura S, Abe K, et al. Three independent genetic profiles based on mucin expression in early differentiated-type gastric cancers: a new concept of genetic carcinogenesis of early differentiated-type adenocarcinomas. Mod Pathol. 2004;17:1223-34.

14. Dreznik A, Purim O, Idelevich E, Kundel Y, Sulkes J, Sulkes A, et al. Gastric cancer: biology and clinical manifestations in Israel. J Surg Oncol. 2011;105:316-22. doi:10.1002/jso. 22078.

15. Jung KW, Park S, Kong HJ, Won YJ, Boo YK, Shin HR, et al. Cancer statistics in Korea: incidence, mortality and survival in 2006-2007. J Korean Med Sci. 2010;25:1113-21.

16. Keinan-Boker L, Noyman N, Chinich A, Green MS, NitzanKaluski D. Overweight and obesity prevalence in Israel: findings of the first national health and nutrition survey (MABAT). Isr Med Assoc J. 2005;7:219-23.

17. Zidan J, Sikorsky N, Basher W, Sharabi A, Friedman E, Steiner M. Differences in pathological and clinical features of breast cancer in Arab as compared to Jewish women in Northern Israel. Int J Cancer 2011. doi:10.1002/ijc.26431.

18. Ghaffari SR, Rafati M, Sabokbar T, Dastan J. A novel truncating mutation in the E-cadherin gene in the first Iranian family with hereditary diffuse gastric cancer. Eur J Surg Oncol. 2010;36: 559-62. 
19. Marie MA, Altahir IE. Relationship between the extent of DNA damage and gastritis in normal and Helicobacter pylori-infected patients. Gut Liver. 2011;5:315-20.

20. Gilboa S, Gabay G, Zamir D, Zeev A, Novis B. Helicobacter pylori infection in rural settlements (Kibbutzim) in Israel. Int $\mathbf{J}$ Epidemiol. 1995;24:232-7.

21. Rabin I, Chikman B, Lavy R, Poluksht N, Halpern Z, Wassermann I, et al. The accuracy of sentinel node mapping according to
$\mathrm{T}$ stage in patients with gastric cancer. Gastric Cancer. 2010;13:30-5.

22. Strong VE, Song KY, Park CH, Jacks LM, Gonen M, Shah M, et al. Comparison of gastric cancer survival following R0 resection in the United States and Korea using an internationally validated nomogram. Ann Surg. 2010;251:640-6.

23. Shin A, Kim J, Park S. Gastric cancer epidemiology in Korea. J Gastric Cancer. 2011;11:135-40. 